\title{
Is Hair Removal Necessary after Crystallized Phenol Treatment in Pilonidal Disease?
}

\author{
Süleyman Kargın ${ }^{a}$ Osman Doğru ${ }^{b}$ Ersin Turan ${ }^{c}$ \\ aDepartment of General Surgery, KTO Karatay University, Medical Faculty, Konya, Turkey; \\ ${ }^{b}$ Department of General Surgery, Konya Training and Research Hospital, Konya, Turkey; \\ 'Department of General Surgery, Beyhekim State Hospital, Konya, Turkey
}

\section{Highlights of the Study}

- Hair removal after crystallized phenol decreases the incidence of pilonidal diseases recurrence.

- Hair removal is needed at least for 30 months following the crystallized phenol procedure.

- Recurrence decreased by $0.8 \%$ every month with hair removal within 30 months.

\section{Keywords}

Pilonidal disease $\cdot$ Crystallized phenol $\cdot$ Hair removal

\begin{abstract}
Objective: The most important cause of posttreatment recurrence of pilonidal sinus disease (PSD) is the reentry of hair into the skin. The study aimed to investigate the effect of hair removal and its duration on the prevention of recurrence after crystallized phenol treatment. Subject and Methods: Patients with PSD who were treated with crystallized phenol treatment were evaluated. Hair in the sacrococcygeal area was removed with depilatory cream before every crystallized phenol procedure, during the treatment, and after treatment once a month for 6 years. Of 1,016 patients, 735 were contacted by telephone or e-mail regarding the frequency of sacrococcygeal hair removal and recurrence. De-
\end{abstract}

mographic and sinus features and crystallized phenol application data of patients treated with crystallized phenol for PSD, as well as recurrences were retrospectively assessed. Results: The mean follow-up time was $46.23 \pm 33$ (range, $11-$ 240) months, with 139 (18.9\%) patients experiencing recurrence. Patients who underwent hair removal experienced significantly less recurrence than those who did not ( $p=$ 0.003 , odds ratio [OR]: 0.54 [95\% Cl: $0.36-0.82]$ ). The OR of recurrence decreased by $0.8 \%$ every month as the hair removal time increased (OR: 0.992, 95\% Cl: 0.985-1.000, $p=$ 0.049 ). The cutoff value for sensitivity was 0.636 , specificity 0.466 , and area under the curve 0.562 in hair removal procedures that lasted for over 30 months. Conclusion: Regular hair removal during, and at least 30 months after, crystallized phenol treatment reduced recurrences in patients with PSD.

(c) 2021 The Author(s)

Published by S. Karger AG, Basel
(C) 2021 The Author(s)

Published by S. Karger AG, Basel

This is an Open Access article licensed under the Creative Commons Attribution-NonCommercial-4.0 International License (CC BY-NC) (http://www.karger.com/Services/OpenAccessLicense), applicable to the online version of the article only. Usage and distribution for commercial purposes requires written permission. 


\section{Introduction}

Although the aetiology of pilonidal sinus disease (PSD) is not fully understood, a high density of hair around the body or natal cleft may be a risk factor for PSD and the presence of body hair after surgical treatment may lead to recurrence $[1,2]$. The importance of body hair removal to prevent the recurrence of PSD after surgery was highlighted in many studies [3-5].

Some authors reported that the primary cause of PSD is the entry of sharp hair fragments into the skin, which can be reduced by bathing [6-8]. Other studies concluded that poor body hygiene and bathing habits were risk factors of PSD and recurrence $[9,10]$ and that bathing at least twice weekly reduces the PSD risk and early postoperative wound complications in PSD $[7,11]$ as it prevents the insertion of hair fragments into the skin, which is occipital or body hair falling from the body into the sacrococcygeal region [12]. The vertical strength of occipital, lumbar, and intergluteal hair from patients with PSD is significantly greater than that from other regions of the body [13]. Harlak et al. [11] reported that the odds of having PSD were 6.33 times higher for people who bathe at least twice weekly than for those who bathe at least thrice weekly [11].

Similarly, hair removal is very important in understanding the aetiology and prevention of recurrence of PSD. Depilatory cream, laser depilation, and razor shaving are common methods of hair removal. Several studies have reported that laser depilation and depilatory cream can prevent recurrence after surgical treatment $[14,15]$; however, razor epilation has become controversial as it can lead to a high recurrence [16] and is thus not recommended in treatment of PSD. To the best of our knowledge, there are no reports on the effect of the duration of body hair removal on PSD recurrence after surgery or assessed nonsurgical treatments. This study aimed to de- termine the necessity of hair removal after crystallized phenol treatment (CPT) of PSD and to identify the ideal duration of hair removal after CPT and the effect of hair removal on the recurrence of the disease.

\section{Patients and Methods}

The study was conducted according to the World Medical Association Declaration of Helsinki on Ethical Principles for Medical Research. Data of 1,026 patients who were treated with CPT at the general surgery outpatient clinics of Konya Training and Research Hospital and Euphrates University School of Medicine with primary PSD between January 1996 and February 2015 were analysed retrospectively. Age, sex, body hair density, sinus features, CPT application data, and number of recurrences were assessed. Upon admission, the density of body hair was visually evaluated, and patients were classified into 3 groups: mild, moderate, and severe hair density (Table 1).

Crystallized phenol treatment was administered as previously described [17]. The patients were asked to clean their hair from the waist to the middle of the thighs with only depilatory creams 1 day before the procedure. Patients were placed in a prone position for the procedure. A thin mosquito clamp was inserted into the sinus after local anaesthesia was administered around the holes. The hair was removed in the sinus cavity, and the skin around the hole was covered by nitrofurantoin pomade (Furacin, EczacıbaşıIllaç San ve Tic. AŞ, İstanbul, Turkey) to prevent chemical irritation. Then, crystallized phenol was administered to the sinus cavity with the same clamp (Botapharma Lab. Ankara, Turkey). Abscess, if present, is drained first before CPT. Patients were allowed to return to their daily activities after the procedure and were followed up a time every 3 weeks after the first procedure. CPT and hair removal with depilatory creams were performed once every 3 weeks. CPT was repeated in case of discharge from the wound during followup. If the sinus hole was closed and the discharge was completely stopped, the treatment was considered successful, indicating healing. Follow-up was started after the treatment. The patients were trained subsequently to remove the hair in this area every month for at least 6 years.

Patients were contacted by telephone and e-mail in February 2017 to record the frequency of hair removal and the presence of recurrence. Patients who could not be contacted were excluded

Table 1. Assessment of body hair density levels

\begin{tabular}{ll}
\hline Mild & $\begin{array}{l}\text { Sparse hair on the dorsal and gluteal region of the back of the body and on chest and abdomen } \\
\text { region in front of the body in men. The presence of sparse blonde hairs or no hair visible in these } \\
\text { areas in women }\end{array}$ \\
\hline Moderate & $\begin{array}{l}\text { Hair from dorsal region to middle of the waist and no hair in gluteal region in men. Sparse hair } \\
\text { on the dorsal and gluteal region of the back of the body in women }\end{array}$ \\
\hline Severe & $\begin{array}{l}\text { Hair on dorsal and gluteal region of the back of the body and on chest and abdomen region in } \\
\text { front of the body frequently and uninterruptedly in men. Extensive hair between dorsal and } \\
\text { gluteal regions in lower back continuously in women }\end{array}$ \\
&
\end{tabular}


from the study. The remaining patients were divided into 6 groups based on the duration of hair removal (Table 2).

Fluid retention in the sinus may be observed in some patients due to pseudo-closure during the controls at 3-week intervals. Therefore, the patients were checked once every 3 weeks and evaluated for occurrence of fluid retention in the sinus or pseudo-closure. We considered it not a relapse but a failure of treatment if there was a recurrent discharge in the sinus hole in $<6$ months after treatment completion. Therefore, the leakages that developed within 6 months after the openings were closed were not considered as relapses. In total, 291 patients who were followed for $<6$ months and could not or did not provide hair removal data via telephone and e-mail were excluded from the study.

\section{Statistical Analysis}

Mean, standard deviation, median, minimum and maximum values, frequency, and percentage figures were used in the descriptive analysis of data. The distribution of variables was analysed us-

Table 2. Responses to items on the questionnaire on hair removal

\section{Never performed}

0-6 months of removal, discontinued thereafter

6 months - 1 year of removal, discontinued thereafter

1-2 years of removal, discontinued thereafter

2-4 years of removal, discontinued thereafter

4-6 years of removal, discontinued thereafter ing the Kolmogorov-Smirnov test. The Mann-Whitney U test was used to analyse quantitative independent data and $\chi^{2}$ qualitative independent variables. The relationship between the groups of the independent variables (duration of hair removal, body hair density, and recurrence) was analysed using logistic regression. Odds ratio (OR) and confidence interval (CI) values were used to measure the significance of data. The ROC curve analysis, sensitivity, specificity, positive and negative predictive value, and area under the curve were used for the cutoff value. The Kaplan-Meier survival analysis was used to determine differences in recurrence rates. The SPSS version 22.0 software package programme was used in all statistical analyses.

\section{Results}

A total of 735 patients were included in the study. The median age of the patients was 26 years and the recurrence rate increased with decreasing age $(p=0.01)$. Male patients had more instances of recurrence. Table 3 shows the demographic data of the patients who experienced recurrence. Most of patients (56.5\%) had moderate, 14 (10.1\%) had mild, and $53(38.1 \%)$ had severe hair density. There was no relationship between the levels of body hair density and recurrence $(p=0.157$, Table 3$)$. The mean number of total openings was 2.49 . The recurrence was higher in patients who have a greater number of total openings, number of CPT application, and healing duration of disease than who have lower values (respectively,

Table 3. Demographic data of patients and recurrence of PSD

\begin{tabular}{|c|c|c|c|c|c|c|c|}
\hline \multirow[t]{2}{*}{ Demographic data } & \multicolumn{2}{|l|}{ No recurrence } & \multicolumn{2}{|l|}{ Recurrence } & \multicolumn{2}{|l|}{ Total } & \multirow[t]{2}{*}{$p$ value } \\
\hline & $\begin{array}{l}\text { mean } \pm \mathrm{SD} \\
(\min -\max ), n(\%)\end{array}$ & median & $\begin{array}{l}\text { mean } \pm \mathrm{SD} \\
(\min -\max ), n(\%)\end{array}$ & median & $\begin{array}{l}\text { mean } \pm \mathrm{SD} \\
(\min -\max ), n(\%)\end{array}$ & median & \\
\hline Age, years & $27.19 \pm 8.42(14-71)$ & 26 & $25.42 \pm 8.55(14-50)$ & 23 & $26.89 \pm 8.46(14-71)$ & 26 & $0.010^{\mathrm{m}}$ \\
\hline \multicolumn{8}{|l|}{ Gender } \\
\hline Male & $527(88.4)$ & & $128(92.1$ & & $655(89.1)$ & & \multirow[t]{2}{*}{$0.020 x^{2}$} \\
\hline Female & $69(11.6)$ & & $11(7.9)$ & & $80(10.9)$ & & \\
\hline \multicolumn{8}{|l|}{ Hair density } \\
\hline Mild & $75(12.6)$ & & $14(10.1)$ & & $89(12.1$ & & \multirow[t]{3}{*}{$0.157 x^{2}$} \\
\hline Moderate & $343(57.6)$ & & $72(51.8)$ & & $415(56.5)$ & & \\
\hline Severe & $178(29.8)$ & & $53(38.1)$ & & $231(31.4)$ & & \\
\hline Number of total openings & $2.36 \pm 1.52(1-12)$ & & $3.07 \pm 2.36(1-21)$ & & $2.49 \pm 1.73(1-21)$ & & $0.003^{\mathrm{m}}$ \\
\hline Follow-up duration, months & $46.53 \pm 32.73(1-228)$ & & $44.38 \pm 34.78(13-240)$ & & $46.13 \pm 33.11(1-240)$ & & $0.131^{\mathrm{m}}$ \\
\hline Number of CPT application & $1.75 \pm 1.18(1-7)$ & & $2.19 \pm 1.62(1-9)$ & & $1.83 \pm 1.28(1-9)$ & & $0.003^{\mathrm{m}}$ \\
\hline Healing duration, weeks & $4.91 \pm 3.60(1-36)$ & & $6.73 \pm 6.06(1-32)$ & & $5.26 \pm 4.23(1-36)$ & & $0.002^{\mathrm{m}}$ \\
\hline \multicolumn{8}{|l|}{ Sinus presentation } \\
\hline Acute chronic & \multicolumn{2}{|l|}{$100(16.8), 496(83.2)$} & \multicolumn{2}{|l|}{$25(18.0), 114(82.0)$} & \multicolumn{2}{|l|}{$125(17.0), 610(83.0)$} & $0.709^{x^{2}}$ \\
\hline Total patients & $596(81.1)$ & & $139(18.9)$ & & $735(100)$ & & \\
\hline
\end{tabular}

Bold values indicate that $p<0.05$ was considered significant. $\chi^{2}, \chi^{2}$ test; ${ }^{m}$, Mann-Whitney $\mathrm{U}$ test; $n$, number; min, minimum; max, maximum; CPT, crystallized phenol treatment; PSD, pilonidal sinus disease. 
Table 4. Comparison of recurrence rates amongst those who performed hair removal and those who did not based on levels of the body hair density

\begin{tabular}{|c|c|c|c|c|c|c|}
\hline \multirow{2}{*}{$\begin{array}{l}\text { Level of body } \\
\text { hair density }\end{array}$} & \multirow[t]{2}{*}{ Hair removal } & \multicolumn{2}{|l|}{ Recurrence } & \multirow[t]{2}{*}{ OR } & \multirow[t]{2}{*}{$95 \% \mathrm{CI}$} & \multirow[t]{2}{*}{$p$ value } \\
\hline & & $\begin{array}{l}\text { no } \\
n(\%)\end{array}$ & $\begin{array}{l}\text { yes } \\
n(\%)\end{array}$ & & & \\
\hline \multirow[t]{2}{*}{ Mild } & Never performed & $11(84.6)$ & $2(15.4)$ & & & \\
\hline & Performed & $64(84.2)$ & $12(15.8)$ & 9.01 & -4.205 to 7.884 & $0.720^{\mathrm{a}}$ \\
\hline \multirow[t]{2}{*}{ Moderate } & Never performed & $75(73.5)$ & $27(26.5)$ & & & \\
\hline & Performed & $268(85.6)$ & $45(14.4)$ & 0.59 & -5.182 to 0.782 & $0.026^{b}$ \\
\hline \multirow[t]{2}{*}{ Severe } & Never performed & $35(61.4)$ & $22(38.6)$ & & & \\
\hline & Performed & $143(82.2)$ & $31(17.8)$ & 0.32 & -5.682 to 1.201 & $0.055^{\mathrm{c}}$ \\
\hline
\end{tabular}

OR was determined by logistic regression analysis. Reference category in logistic regression analysis used the group who did not perform hair removal. Bold values indicate that $p<0.05$ was considered significant. OR, odds ratio; CI, confidence interval. ${ }^{a}$ Hair removal (never/any). ${ }^{b}$ Levels of body hair density. ${ }^{c}$ Hair removal (never/ any)* levels of body hair density interaction

Table 5. Recurrence rates based on the duration of hair removal

\begin{tabular}{|c|c|c|c|c|c|c|}
\hline & $\begin{array}{l}\text { no } \\
n(\%)\end{array}$ & $\begin{array}{l}\text { yes } \\
n(\%)\end{array}$ & $\begin{array}{l}\text { total } \\
n(\%)\end{array}$ & OR & $95 \% \mathrm{CI}$ & $p$ value \\
\hline Never performed & $126(73.3)$ & $46(26.7)$ & $172(23.4)$ & & & \\
\hline Performed any duration & $470(83.5)$ & $93(16.5)$ & $563(76.6)$ & 0.540 & $0.367-0.822$ & 0.003 \\
\hline 0-6 months performed & $36(87.3)$ & $5(12.2)$ & $41(5.6)$ & 0.380 & $0.141-1.028$ & \\
\hline $2-4$ years performed & $224(82.1)$ & $49(17.9)$ & $273(37.1)$ & 0.599 & $0.379-0.947$ & \\
\hline 4-6 years performed & $111(85.4)$ & $19(14.6)$ & $130(17.7)$ & 0.469 & $0.259-0.848$ & \\
\hline
\end{tabular}

OR and $p$ value was determined by logistic regression. Reference category in logistic regression analysis used the group who did not perform hair removal. Bold values indicate that $p<0.05$ was considered significant. OR, odds ratio; CI, confidence interval.

$p=0.003, p=0.003, p=0.002)$. The mean follow-up time was $46.23 \pm 33$ (range, 11-240) months. Recurrence was observed once in $126(90.6 \%)$ patients, twice in $11(7.9 \%)$ patients, and thrice in $2(1.5 \%)$ patients. Eight $(61.5 \%)$ out of 13 who experienced recurrence at least twice $(11+2)$ were performed the hair removal for $<1$ year. Five (38.5\%) out of 13 who experienced recurrence at least twice were performed hair removal for 2-6 years. Additionally, men with mild body hair density had a lower rate of recurrence than women with the same hair density (OR: 0.36 [0.101.27]), whilst men with moderate and severe densities had a higher rate recurrence than women with the same densities (OR: 1.44 [0.59-3.53] and OR: 4.91 [0.63-38.04]; sex, $p=0.475$; body hair density, $p=0.824$; gender*body hair density interactions, $p=0.067$ ).
The recurrence rates based on the body hair density of those who performed hair removal and those who did not are shown in Table 4 . Whilst the rate of recurrence was not significant between groups with mild hair density, it was significantly lower in those with moderate and severe hair densities (OR: 0.59, OR: $0.32, p=0.026$ and $p=0.05$, respectively; Table 4 ).

The recurrence rates based on the duration of hair removal are presented in Table 5. A total of 139 (18.9\%) patients experienced recurrence, amongst which 46 (33\%) patients did not perform hair removal. The number of patients who did not perform hair removal was 172 (23.4\%). Recurrence was observed in 93 (16.5\%) out of 563 patients who performed hair removal. Those who performed hair removal experienced a significant de- 
Fig. 1. Groups' OR distribution based on duration of hair removal. OR, odds ratio.

Fig. 2. Kaplan-Meier survival analyses of patients with recurrent PSD. PSD, pilonidal sinus disease.
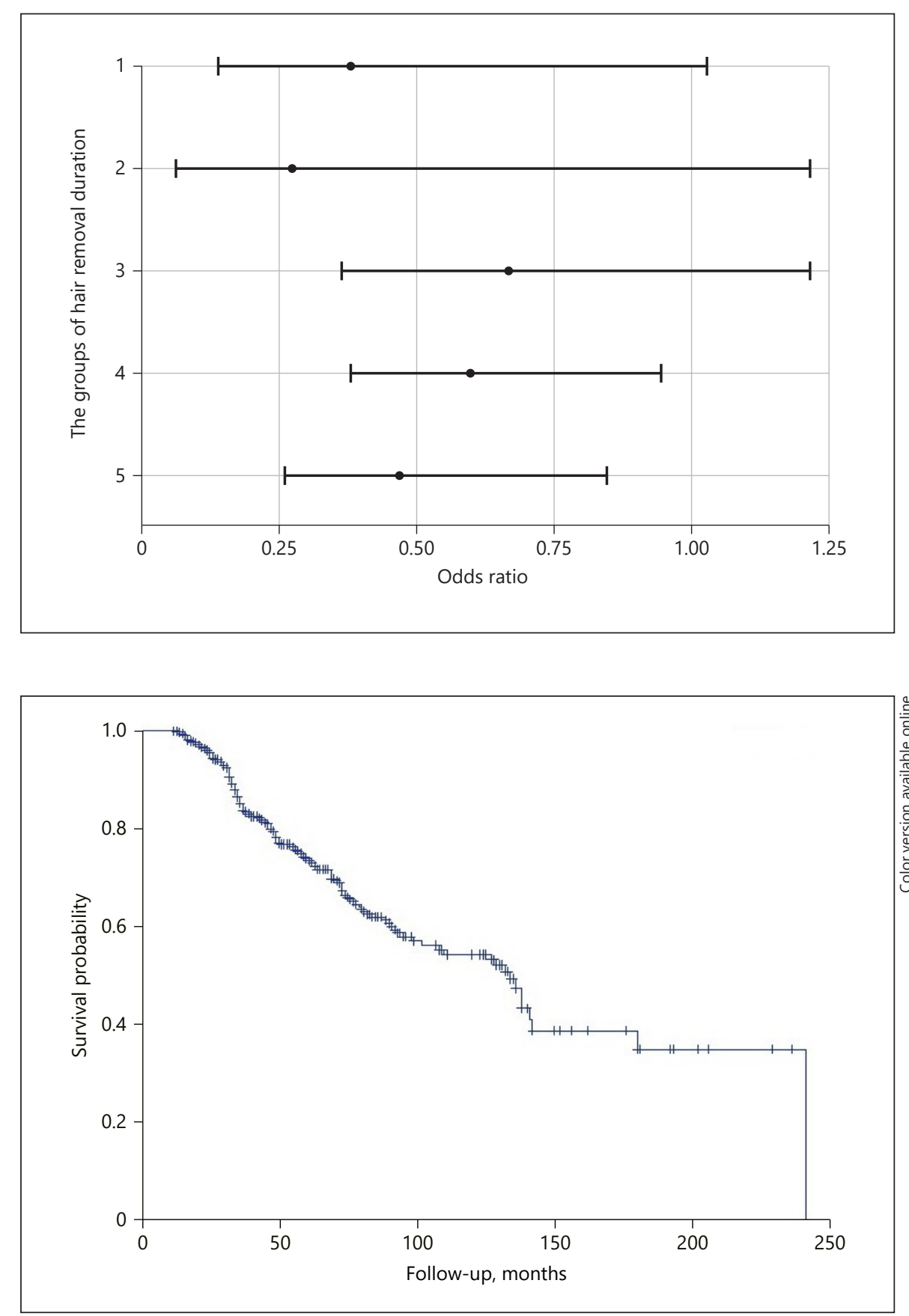

crease in recurrence rates than those who did not $(p=$ 0.003, OR: 0.54 [0.36-0.82]) (Table 5; Fig. 1).

Although recurrence rates decreased in all groups in contrast with the duration of hair removal $(p=0.054$, Fig. 2), there was a significant decrease especially in the patients who removed hair for 2-4 and 4-6 years (OR: 0.599 [95\% CI, respectively: 0.379-0.947], OR: 0.469 [95\% CI: $0.259-0.848]$ ). According to logistic regression analy- sis, the OR of recurrence decreased by $0.8 \%$ every month in contrast with the duration of hair removal $(\mathrm{OR}=0.992$, $95 \% \mathrm{CI}=0.985-1.000, p=0.049$ ). In addition, the ROC curve analysis showed that the sensitivity for cutoff value was 0.636 , specificity 0.466 , and area under the curve 0.562 in hair removal procedures performed in at least 30 months. 


\section{Discussion}

PSD is currently widely considered an acquired disease, mainly caused by the excessive amount of free hair [18]. Free hair in the sacrococcygeal region tends to enter the subcutaneous area and cause inflammation due to local trauma and other physical forces. The formations of PSD in areas where ingrown hairs exist, such as those frequently seen in the hands of barbers, support this theory $[11,19]$.

Although hair is the main reason for the development of this disease, hairy body structure causing hair accumulation in these regions, excessive hair loss, narrow and deep natal cleft, and poor body hygiene increase the likelihood of PSD development are also considered etiological factors [20]. Therefore, body hair density and excess hair loss are important in the aetiology of PSD. We evaluated the body hair density of all our patients before PSD treatment. According to our results, recurrence rates were higher in men with moderate and severe body hair densities than women with the same hair densities, but lower in men with mild hair density than women with same density. However, as the body hair density in men is frequently noted at moderate and severe densities, general body hair density could cause the higher recurrence rate in men.

To prevent recurrences, regular body hygiene and removal of free hairs from the sacrococcygeal region are important, as previously emphasised $[4,11]$. Good hygiene enables the removal of hair accumulated in the sacrococcygeal region from the body. Thus, the more frequently a person bathes, the more hair in this area is destroyed before possible insertion into the skin. Similarly, regular removal of hair in this area leads to decrease in the amount of hair that falls on this area. However, it is not clear which method and how long hair removal should be performed to prevent recurrences. Various methods including hair removal creams, waxing, epilators, razor shaving, and laser depilation can be used. Generally, methods that do not cause trauma to the skin and prevent hair formation are preferred. Epilators and shaving blades are not recommended because they increase recurrences $[16,21]$. Laser epilation has been reported to give the best results in preventing recurrence of PSD [22, 23]. However, laser epilation is often not preferred because of its high cost and reluctance of individuals. Thus, hair removal creams are preferred due to easy application at home and very few side effects. However, its disadvantage is the need to repeat the process at regular intervals because creams shed the hair present at the site and reduce their rigidity instead of reducing the number of hair follicles.
In the present study, all patients were asked to perform hair removal 1 day before every procedure during the treatment period and to perform regular hair removal at intervals of 4 weeks during 6 years after completion of treatment. To our knowledge, this is the first study to evaluate the duration of hair removal and its effects on recurrence of PSD after treatment and the need for hair removal after the CPT based on the hair density. We determined that regular hair removal should be performed for at least 30 months to reduce recurrences. Prolonging hair removal duration leads to reduction in recurrence (Table 5). However, the rate of recurrence was not significant between groups with mild hair density, but in those with moderate and severe hair densities, it was significantly lower in patients who performed hair removal than those who did not (OR: 0.59 vs. $0.32, p=0.026$, Table 4). Patients with moderate and severe hair density should periodically perform hair removal after the CPT.

Limitations of this study include the fact that it was performed retrospectively and required long-term patient follow-up. Some of the patients could not be reached and this caused loss of data.

\section{Conclusion}

Regular hair removal in the sacrococcygeal region with depilatory creams should be performed once a month for at least 30 months to reduce recurrences following CPT. However, in patients whose pilosity levels were mild, there was no relationship between recurrence and hair removal. There was higher recurrence rate in patients who have moderate and severe body hair density and who did not perform hair removal. Because regular hair removal during and after CPT reduces recurrence of PSD, long-term and regular hair removal after CPT, which is the most commonly performed nonoperative treatment in PSD, is necessary.

\section{Statement of Ethics}

This study was conducted in accordance with the World Medical Association Declaration of Helsinki. Ethics committee approval was not required as the study was conducted through retrospectively scanning of files.

\section{Conflict of Interest Statement}

The authors report no conflict of interest. 


\section{Funding Sources}

This research did not receive any specific grant.

\section{Author Contributions}

Kargin S., Doğru O.: design of the study and interpretation of data; Kargın S., Turan E.: drafting and revising; and Doğru O., Kargin S.: final approval of the manuscript.

\section{References}

1 Doll D, Luedi MM, Wysocki AP. Pilonidal sinus disease guidelines: a minefield? Tech $\mathrm{Co}-$ loproctol. 2016 Apr;20(4):263-4.

2 Conroy FJ, Kandamany N, Mahaffey PJ. Laser depilation and hygiene: preventing recurrent pilonidal sinus disease. J Plast Reconstr Aesthet Surg. 2008 Sep;61(9):1069-72.

3 Kandamany N, Mahaffey PJ. The importance of hair control and personal hygiene in preventing recurrent pilonidal sinus disease. J Plast Reconstr Aesthet Surg. 2008 Aug;61(8): 986-7.

4 Pronk AA, Eppink L, Smakman N, Furnee EJB. The effect of hair removal after surgery for sacrococcygeal pilonidal sinus disease: a systematic review of the literature. Tech Coloproctol. 2018 Jan;22(1):7-14.

5 Chintapatla S, Safarani N, Kumar S, Haboubi N. Sacrococcygeal pilonidal sinus: historical review, pathological insight and surgical options. Tech Coloproctol. 2003 Apr;7(1):3-8.

6 Karydakis GE. New approach to the problem of pilonidal sinus. Lancet. 1973 Dec 22; 2(7843):1414-5.

7 Ferhatoglu MF, Kartal A, Ekici U, Kebudi A. Effects of bathing habits on postoperative wound complications following sacrococcygeal pilonidal sinus surgery: a retrospective analysis of 67 adolescent patients. Wounds. 2019 Nov;31(11):292-6.

8 Hosseini SV, Rezazadehkermani M, Roshanravan R, Muzhir Gabash K, Aghaie-Afshar M. Pilonidal disease: review of recent literature. Ann Colorectal Res. 2014;2(2):e19705.
9 Bolandparvaz S, Moghadam Dizaj P, Salahi R, Paydar S, Bananzadeh M, Abbasi HR, et al. Evaluation of the risk factors of pilonidal sinus: a single center experience. Turk J Gastroenterol. 2012;23(5):535-7.

10 Yildiz T, Elmas B, Yucak A, Turgut HT, Ilce Z. Risk factors for pilonidal sinus disease in teenagers. Indian J Pediatr. 2017 Feb;84(2):134-8.

11 Harlak A, Mentes O, Kilic S, Coskun K, Duman K, Yilmaz F. Sacrococcygeal pilonidal disease: analysis of previously proposed risk factors. Clinics. 2010 Feb;65(2):125-31.

12 Bosche F, Luedi MM, van der Zypen D, Moersdorf P, Krapohl B, Doll D. The hair in the sinus: sharp-ended rootless head hair fragments can be found in large amounts in pilonidal sinus nests. World J Surg. 2018 Feb; 42(2):567-73.

13 Doll D, Bosche FD, Stauffer VK, Sinicina I, Hoffmann S, van der Zypen D, et al. Strength of occipital hair as an explanation for pilonidal sinus disease caused by intruding hair. Dis Colon Rectum. 2017 Sep;60(9):979-86.

14 Grabowski J, Oyetunji TA, Goldin AB, Baird $\mathrm{R}$, Gosain A, Lal DR, et al. The management of pilonidal disease: a systematic review. J Pediatr Surg. 2019 Nov;54(11):2210-21.

15 Minneci PC, Halleran DR, Lawrence AE, Fischer BA, Cooper JN, Deans KJ. Laser hair depilation for the prevention of disease recurrence in adolescents and young adults with pilonidal disease: study protocol for a randomized controlled trial. Trials. 2018 Nov 1; 19(1):599.
16 Petersen S, Wietelmann K, Evers T, Hüser N, Matevossian E, Doll D. Long-term effects of postoperative razor epilation in pilonidal sinus disease. Dis Colon Rectum. 2009 Jan; 52(1):131-4.

17 Dogru O, Camci C, Aygen E, Girgin M, Topuz O. Pilonidal sinus treated with crystallized phenol: an eight-year experience. Dis Colon Rectum. 2004 Nov;47(11):1934-8.

18 Armstrong JH, Barcia PJ. Pilonidal sinus disease. The conservative approach. Arch Surg. 1994 Sep;129(9):914-9.

19 Ricci F, Passarelli F, Fiorentini S, Di Lella G. "Interdigital pilonidal sinus in a hairdresser" a case report. Dermatol Ther. 2018 May; 31(3):e12594.

20 Bascom J. Pilonidal disease: origin from follicles of hairs and results of follicle removal as treatment. Surgery. 1980 May;87(5):567-72.

21 Toosi P, Sadighha A, Sharifian A, Razavi GM. A comparison study of the efficacy and side effects of different light sources in hair removal. Lasers Med Sci. 2006 Apr;21(1):1-4.

22 Schulze SM, Patel N, Hertzog D, Fares LG 2 nd. Treatment of pilonidal disease with laser epilation. Am Surg. 2006 Jun;72(6):534-7.

23 Landa N, Aller O, Landa-Gundin N, Torrontegui J, Azpiazu JL. Successful treatment of recurrent pilonidal sinus with laser epilation. Dermatol Surg. 2005 Jun;31(6):726-8. 